\title{
INFECTION WITH DIFFERENT SPECIES OF LEPTOSPIRES IN HUSBAND AND WIFE
}

\author{
BY \\ M. S. PATHY* \\ From Llwynypia Hospital, Rhondda
}

(RECEIVED FOR PUbliCATION AUGUST 22, 1959)

\begin{abstract}
Leptospirosis occurring in a husband and wife is described. Both were responsible for cleaning up the excreta of a recently acquired puppy. The wife developed leptospirosis canicola, and three months later the husband developed leptospirosis icterohaemorrhagica. Difficulty was experienced in ascertaining the infecting species of leptospire in the husband owing to the agglutination tests giving an equal rise and fall in titres for both $L$. icterohaemorrhagiae and L. canicola. The diagnosis was only confirmed after cross-absorption tests had been done.

The husband developed pulmonary complications on the nineteenth day. The radiological appearances of the chest are discussed, together with a brief review of the literature on the radiological manifestations of pulmonary lesions in Weil's disease.
\end{abstract}

Although more than 40 different strains of leptospires have been recognized by serological methods, only Leptospira icterohaemorrhagiae, which produces Weil's disease, and Leptospira canicola, the common spirochaetal infection of dogs, are normally associated with human infection in Britain. Keal (1957) has, however, reported a case of leptospirosis due to Leptospira grippotyphosa occurring in a Malayan who had arrived in England by air from Malaya 10 days previously. Leptospirosis icterohaemorrhagica is relatively common, especially among farm workers, sewer workers, miners, and fish cleaners. Since the description by Baber and Stuart (1946) of the first recognized human infection with $L$. canicola in this country, 30 cases occurring in Britain have been reported in the literature. Broom (1951a) noted that although 15 to 20 cases of $L$. canicola were recognized annually in Britain, the incidence was certainly higher.

The serological diagnosis of leptospirosis is generally straightforward, but occasionally it may be equivocal or definitely misleading. Case 1 illustrates the difficulty that may be experienced in determining the exact species of leptospire responsible for the disease, especially when the clinical picture and logical sequence of events also point to a species other than the true culprit. Of further interest are the pulmonary complications in Case 1.

*Present address: Amersham General Hospital, Bucks.

\section{Case Reports}

Case 1.-A miner, aged 50, was admitted to hospital on May 2, 1955. He had been in good health until six days previously when he complained of marked weakness and of pains in the lumbar region and calves of the legs. The following day he had severe frontal and occipital headache, and rigors which occurred several times each day until admission. Before admission to hospital he had been working on the surface at a colliery for a year, and he was quite emphatic that there were no rats near his place of work.

In December, 1954, the patient bought a one-monthold puppy; for four months both he and his wife frequently mopped up pools of urine left by the dog.

On admission the temperature was $101^{\circ} \mathrm{F}$. with a pulse rate of 104 per minute. He appeared ill and the conjunctivae were obviously injected. Moderate neck stiffness and a positive Kernig's sign were present. A few small abrasions were noted on the fingers of both hands and the axillary lymph glands were enlarged. Two days later neck and back stiffness had become pronounced.

Investigations.-A blood count showed 7,200 leucocytes per c.mm. (polymorphs $56 \%$, lymphocytes $30 \%$, monocytes $14 \%$ ). Haemoglobin was $13 \mathrm{~g} . \%$, the E.S.R. $46 \mathrm{~mm}$. in the first hour. The cerebrospinal fluid was slightly opalescent, with 138 cells per c.mm. (lymphocytes $90 \%$ ), total protein $165 \mathrm{mg}$. per $100 \mathrm{ml}$. with a moderate excess of globulin, chlorides $700 \mathrm{mg}$. per $100 \mathrm{ml}$., sugar $44 \mathrm{mg}$. per $100 \mathrm{ml}$.; no organisms were seen on direct examination and on culture it was sterile; the Wassermann reaction was negative. 
The urine showed a cloud of albumin, but centrifuged deposit showed only one granular cast per 20 highpower fields. Blood urea was $30 \mathrm{mg}$. per $100 \mathrm{ml}$., serum bilirubin $0.4 \mathrm{mg}$. per $100 \mathrm{ml}$., serum alkaline phosphatase 12 units, thymol turbidity 2 units per $100 \mathrm{ml}$., and a colloidal gold test was negative. Blood culture was sterile. A radiograph of the chest two days after admission showed a slight diffuse mottling due to pneumoconiosis.

The serum agglutination reactions were as follows:

\begin{tabular}{c|c|c}
\hline Date of Specimen & L. canicola & L. icterohaemorrhagiae \\
\hline 3.5 .55 & $1 / 300$ & $1 / 300^{1}$ \\
11.5 .55 & $1 / 1,000$ & $1 / 300^{2}$ \\
29.5 .55 & $1 / 1,000$ & Trace at $1 / 1,000$ \\
18.7 .55 & $($ Partial) $1 / 3,000$ & $1 / 1,000^{2}$ \\
5.1 .55 & $1 / 1,000$ & $($ Partial) $1 / 3,000$ \\
1.4 .56 & $1 / 300$ & $1 / 1,000^{2}$ \\
15.7 .57 & $1 / 300$ & $1 / 300^{2}$ \\
& $1 / 30$ & $1 / 300^{2}$ \\
& & $1 / 100^{2}$ \\
\hline
\end{tabular}

1 Tested by Dr. R. W. Harvey. ${ }^{2}$ Tested by Dr. J. C. Broom.

On May 29, 1955, a cross-absorption test was performed by Dr. J. C. Broom, who reported that the results indicated that the patient was suffering from true Weil's disease, but that the results were not as clear cut as he really liked, and he therefore suggested a further cross-absorption test in one month. A further specimen of blood taken on July 18, 1955, was reported on by Dr. Broom as follows:

" After absorption with L. icterohaemorrhagiae the serum was negative with both $L$. icterohaemorrhagiae and $L$. canicola from 1/30 upwards (this was the lowest dilution tested). After absorption with $L$. canicola, it was negative with $L$. canicola from 1/30 upwards, but still agglutinated $L$. icterohaemorrhagiae to $1 / 300$ with a trace at $1 / 1,000$."

Unfortunately the puppy could not be investigated as the patient had ordered his wife to have it destroyed after overhearing a discussion in the ward about the animal.

Treatment with penicillin, 500,000 units eight-hourly, was begun on the second day after admission and continued for $\mathbf{1 0}$ days. His condition improved, but on the nineteenth day of admission he complained of a severe, sharp stabbing pain on both sides of the chest, which was aggravated by deep breathing. Examination of the chest revealed signs of an area of consolidation at both bases. Treatment with oxytetracycline, $500 \mathrm{mg}$. six-hourly, was begun. On the following day the temperature rose to $100^{\circ} \mathrm{F}$. $\left(37.8^{\circ} \mathrm{C}\right.$.) and it remained raised for the ensuing four days. The patient then gradually improved, but the impression was formed that the antibiotic treatment was playing little or no part in the improvement.

Further investigations at this stage: Blood count, 4,000 leucocytes per c.mm. (polymorphs $64 \%$, lymphocytes $27 \%$, monocytes $9 \%$ ) ; E.S.R. $20 \mathrm{~mm}$. in the first hour. No pathogenic organisms were found in several specimens of sputum and no cold agglutinins were detected in serum. A chest radiograph taken in the ward two days after the onset of chest pain showed small areas of patchy consolidation over both lower zones with a small pleural effusion at the left base. Nine days later, a further chest radiograph showed that the effusion had cleared, but that there were still small irregular areas of consolidation in the left lower lobe and lingula. A radiograph on June 16 still showed a small area of consolidation in the lingula. A final chest radiograph taken six months later was normal, apart from slight mottling due to pneumoconiosis.

Case 2.-A housewife, aged 48, the wife of Case 1, developed severe frontal headache and pyrexia in February, 1955. The following day she complained of general weakness and of pains in the calves of the legs and pain and stiffness in the back. She had marked photophobia and vomited frequently. (She ascribed her condition to "gastric flu.") She could not remember if she had had any cuts or scratches on her hands at the time of the illness. After two weeks her condition slowly improved, but she did not feel really well for a further three weeks.

Examination three weeks after her husband's admission to hospital revealed no abnormal physical signs.

A serum agglutination reaction on June 25,1955 , was reported on by Dr. Broom as:

"The patient's serum is positive to $1 / 300$ with a trace at $1 / 1,000$ with $L$. canicola and shows only traces of agglutination in low dilutions with L. icterohaemorrhagiae."

Serum from the son, aged 24, and daughter, aged 17 , of Cases 1 and 2 failed to agglutinate suspensions of L. icterohaemorrhagiae and L. canicola (Dr. R. W. Harvey). Neither the son nor the daughter had ever cleaned up the excreta from the puppy.

\section{Discussion}

In leptospirosis agglutinins normally appear about the end of the first week after the onset of symptoms, and reach a maximum between the third and fifth week of the disease, but Broom (1951b) mentions a few cases in which antibody production was delayed for more than three weeks. In the early stages of leptospirosis a patient's serum not uncommonly agglutinates more than one species of leptospire. Occasionally the titre of agglutination for a related heterologous type may be as high or even higher than the titre for the infecting species (Gispen and Schüffner, 1939). As the disease progresses the titres for the infecting species usually rise, while the heterologous titres fall. In Case 1 the heterologous titre remained as high as the homologous titre for at least 11 months, which is exceptional (Broom, personal communication); indeed, the correct diagnosis was only obtained after crossabsorption tests had been done. A diagnosis 
based on an agglutination test only may be misleading as in the case recorded by O'Connell and Broom (1952).

The clinical evidence in Case 1 pointed to a leptospirosis canicola infection. No history of contact with rats could be obtained. Though classed as a miner, he had been working on the surface at the colliery as a rider, i.e., he was responsible for transporting slack in special wagons, and he was quite adamant that his place of work was dry and free from rats. However, the waste slack from underground could have been contaminated with rats' urine. It appears certain that his wife (Case 2) had had leptospirosis canicola three months before his own illness; yet both husband and wife shared the duty of mopping up pools of urine left by the puppy. The animal was apparently quite fit. Broom and MacIntyre (1948) have estimated that approximately 25 to $40 \%$ of dogs in England become infected with $L$. canicola at some period during their lifetime. Many of these dogs are symptomless carriers. It was not possible to prove that the puppy in this case was a carrier of L. canicola, as it was unfortunately destroyed without our knowledge.

The pulmonary manifestations of leptospirosis do not appear to have been generally recognized in Britain. (A more detailed description of the radiological appearances of pulmonary lesions in leptospirosis will be described elsewhere.) Moeschlin (1943), in Switzerland, described four cases of leptospirosis icterohaemorrhagica which, on radiological examination, showed bilateral patchy pulmonary infiltration. Extensive haemorrhage into the lung parenchyma was found in one patient at necropsy. Radiological signs of areas of patchy consolidation in both lungs were also described by Havens, Bucher, and Reimann (1941) in two out of seven men with confirmed Weil's disease. One of the two cases died and at necropsy both lungs showed a patchy haemorrhagic type of consolidation in the lower lobes. "Fleeting lung infiltrations" in the absence of physical signs were noted by Gsell (1949). Silverstein (1953), in a review of the radiological findings in Weil's disease, found radiological evidence of " pulmonary infiltrations" in four out of 33 patients with confirmed leptospirosis icterohaemorrhagica. Three cases were described in detail with reproductions of the chest radiographs. The presence of small irregular mottling over the lower and middle zones of both lungs was evident in the chest radiograph of two cases. A third case had a large area of apparent consolidation at the right lower lobe ; at necropsy, however, both lungs were generally oedematous, and on microscopy the alveoli were seen to be filled with red blood cells, the right lower lobe appearing no different from the rest of the lung. It is interesting to note that several of the reported cases of Weil's disease first presented themselves as cases of acute respiratory infection.

The literature on the pathology of pulmonary lesions in leptospirosis is scanty, but a study of the necropsy findings reveals a fairly consistent picture. In severe cases the lungs are oedematous and the alveoli packed with red blood cells. The haemorrhagic areas may be small and localized or they may be extensive; they are generally bilateral, though rarely symmetrical. Occasionally small effusions are present. The cause of these haemorrhagic areas in the lung is uncertain. Haemorrhagic manifestations such as petechiae, epistaxis, haemoptyses, haematemesis, and melaena are not uncommon in Weil's disease. At necropsy large haemorrhages may be found in the intestinal wall, while in the kidneys there may be subcapsular and capillary haemorrhages. Experimental infection of guinea-pigs with L. icterohaemorrhagiae results in widespread haemorrhages in the lung, due to capillary damage.

The possibility that the pulmonary lesions in the first patient were due to an intercurrent bronchopneumonia cannot be entirely ruled out. The radiological picture was not typically that of bronchopneumonia, but was very similar to some of the reported cases of leptospirosis with pulmonary manifestations. The white cell count was not raised nor was the erythrocyte sedimentation rate at the time of the lung complication, and no pathogenic organisms were found in several specimens of sputa.

If patients employed in occupations commonly associated with the presence of rats present with acute chest infections, and where the chest radiological appearances are similar to those described above, the diagnosis of Weil's disease is always worth considering.

I wish to thank Dr. J. C. Broom, of the Wellcome Laboratories of Tropical Medicine, and Dr. R. W. S. Harvey, of the Public Health Laboratories, Cardiff, for permission to quote their agglutination results.

\section{REFERENCES}

Baber, M. D., and Stuart, R. D. (1946). Lancet, 2, 594

Broom, J. C. (1951a). Monthly Bull. Minist. Hlth Lab. Serv., 10, 258 - (1951 b). Brit. med. J., $2,689$.

and MacIntyre, A. B. (1948). Vet. Rec., 60, 487.

Gispen, R., and Schüffner, W. (1939). Zbl. Bakt., I. Abt., 144, 427.

Gsell, O. (1949). Ergebn. inn. Med. Kinderheilk., n.s. 1, 367.

Havens, W. P., Bucher, C. J., and Reimann, H. A. (1941).' J. Amer. med. Ass., 116, 289.

Keal, E. E. F.'(1957). Lancet, 1, 720.

Moeschlin, S. (1943). Schweiz. med. Wschr., 73, 1227

O'Connell, P. J., and Broom, J. C. (1952). Lancet, 1, 1088

Silverstein, C. M. (1953). Radiology, 61, 327. 